\title{
Complex alarm strategy in the most basal termite species
}

\author{
Olivier Delattre $^{1,2,3}$ • David Sillam-Dussès ${ }^{2,3,4}$ - Vojtěch Jandák ${ }^{5}$ Marek Brothánek ${ }^{5}$. \\ Karel Rücker ${ }^{6}$ - Thomas Bourguignon $^{1}$ - Blahoslava Vytisková ${ }^{1}$. Josef Cvačka ${ }^{6}$. \\ Ondřej Jiř́ččk ${ }^{5}$ Jan Šobotník ${ }^{1}$
}

Received: 12 May 2015 / Revised: 3 September 2015 / Accepted: 8 September 2015 /Published online: 1 October 2015

(C) Springer-Verlag Berlin Heidelberg 2015

\begin{abstract}
Studying basal taxa often allows shedding a light on the evolution of advanced representatives. The most basal termite species, Mastotermes darwiniensis, possesses unique morphological and behavioural traits, of which many remain scarcely studied. For these reasons, we conducted a comprehensive study of the alarm communication in this species and compared its components to behavioural modes described in other termites. In M. darwiniensis, the alarm is communicated by substrate-borne vibrations resulting from vertical vibratory movements. Another similar behaviour consists in longitudinal movements, by which the alarm is delivered to other termites in contact with alerted individual. Both these two behavioural modes could be used in synergy to create complex
\end{abstract}

Communicated by W. O. H. Hughes

Electronic supplementary material The online version of this article (doi:10.1007/s00265-015-2007-9) contains supplementary material, which is available to authorized users.

Olivier Delattre

delattre.oliv@gmail.com

1 Faculty of Forestry and Wood Sciences, University of Life Sciences, Kamýcká 129, 16521 Prague 6-Suchdol, Czech Republic

2 Institute of Research for Development, Sorbonne Universités, Paris, France

3 UMR 242, Institute of Ecology and Environmental Sciences of Paris, Bondy, France

4 Laboratory of Experimental and Applied Ethology - EA 4443, Université Paris 13-Sorbonne Paris Cité, Villetaneuse, France

5 Faculty of Electrical Engineering, Czech Technical University in Prague, Technická 2, 16627 Prague 6, Czech Republic

6 Institute of Organic Chemistry and Biochemistry, Academy of Sciences of the Czech Republic, Flemingovo nám. 2, 16610 Prague 6, Czech Republic movements. M. darwiniensis also uses chemical alarm signals produced by labial gland secretion, in contrast to Neoisoptera in which this function is fulfilled exclusively by the frontal gland secretion. Moreover, we demonstrated in M. darwiniensis the presence of a positive feedback mechanism thought to occur exclusively in the crown group Termitidae. This positive feedback consists in both oscillatory movements of alerted individuals in response to alarm signals and release of alarm pheromone by excited soldiers. Our results confirm that $M$. darwiniensis is a remarkable example of mosaic evolution, as it combines many primitive and advanced features, and its alarm communication clearly belongs to the latter category.

Keywords Defence $\cdot$ Labial glands $\cdot$ Vibroacoustic communication - Chemical communication · Positive feedback · Mastotermes darwiniensis

\section{Introduction}

Termites (traditionally order Isoptera; Blattodea: Termitoidea sensu Lo et al. 2007) are often labelled ecosystem engineers (see for example Jouquet et al. 2006) and have crucial ecological impact in warm areas (Bignell and Eggleton 2000), where they decompose plant material at various stages of degradation. They may reach enormous population density in the tropics, sometimes up to 1000 individuals per square metre (Eggleton et al. 1996) and represent an important resource for a wide variety of predators and parasites (Deligne et al. 1981; Grassé 1986). In response, termites have developed a multitude of active and passive defensive traits. The active defences comprise morphological (Deligne et al. 1981), chemical (Prestwich 1984; Šobotník et al. 2010a) and behavioural (Šobotník et al. 2008a; 2010b; 2012) adaptations present 
predominantly in soldiers, while passive defence include cryptic way of life and nest fortification preventing attacks from non-specialist predators (Noirot and Darlington 2000).

Alarm communication triggers particular caste-specific responses, including the recruitment of specialized defenders, the soldiers, and retreat of vulnerable individuals, such as workers, larvae and nymphs (Reinhard and Clément 2002; Šobotník et al. 2008b). But while alarm signals in termites are known to be mediated by two different sensorial channels (vibroacoustic and olfactory, see Connétable et al. 1999; Röhrig, et al. 1999; Reinhard and Clément 2002; Hager and Kirchner 2013), they have never been investigated together in any termite species until recently (Cristaldo et al. 2015).

Vibroacoustic communication is common among insects (Greenfield 2002) and is used in a wide array of contexts, such as mating, foraging, predation or predator avoidance (see Hill 2009 for a review). It is studied in details in social taxa such as ants, bees and wasps (Kirchner 1997; Cocroft and Rodríguez 2005; Hunt and Richard 2013). Vibroacoustic alarm signals are known in eusocial taxa and comprise of two basic categories: (i) stridulation, i.e. producing air-borne vibrations by rubbing a ridge over stripped or toothed area, and (ii) tapping which consists in hitting the nestmates or the substrate to produce substrate-borne vibration. While both means of vibratory alarm are known in hymenopterans, only the latter occurs in termites (for a review see Hunt and Richard 2013). Perception of substrate vibrations is considerably more spread compared to air vibrations perception and certainly predated occurrence of sense of hearing (Hill 2001). All termites and Cryptocercus roaches, sister group of termites (Lo et al. 2000; Inward et al. 2007a), are able to spread the alarm signals through vibratory movements (Bell et al. 2007). Termite vibratory alarm behaviour was first described by Howse (1962, 1964, 1965b) who identified particular modes of signalling according to the axis along which the body shakes. Longitudinal oscillatory movements (OMs) are series of back-and-forth jerks, while vertical OMs are series of downward percussions, which can be associated with longitudinal OMs and create together complex OMs. The signals might be transmitted either by direct contact between individuals (Kettler and Leuthold 1995; Šobotník et al. 2008b) or up to several metres (Röhrig, et al. 1999; Hager and Kirchner 2013) as substrate-borne vibrations perceived by the subgenual organ (Howse 1962, 1965a; Chapman 1998). During OMs, the head and/or the abdomen can hit the floor and/or the ceiling of the galleries (tunnels within or outside the nest), often producing sounds audible to man (Howse 1964, 1965b; Stuart 1988). The main functional significance of these movements is to create substrate vibrations, which trigger caste-specific alarm reactions of nestmates (Stuart 1988; Connétable et al. 1998, 1999; Röhrig et al. 1999). In basal species, the signals are produced both by workers and soldiers, and the vibratory sequences (bursts) consist of an unstable number of beats, while the signals of advanced species are produced only by soldiers and consist of a stable number of beats per burst (Stuart 1988). The most complex signals occur in Macrotermitinae (Termitidae), in which soldiers vibrate in response to perception of nestmates' vibratory signal, spreading the signal throughout the colony by a positive feedback mechanism (Röhrig, et al. 1999; Hager and Kirchner 2013). This increases the efficiency of alarm propagation inside the group, which then can react to threats quicker by recruiting more defenders in order to minimise the losses.

Chemical communication certainly represents the dominant mean of information exchange in social insects (Billen and Morgan 1998; Richard and Hunt 2013). Chemical mediators of intraspecific communication, the pheromones, are secreted from exocrine glands (Billen 2011) and are perceived by specialized chemoreceptors located predominantly on the antennae (Wyatt 2003). The alarm pheromones belong to communication repertoire of most social insects, such as ants (Bradshaw et al. 1975; Wheeler et al. 1975; Hughes et al. 2001; Fujiwara-Tsujii et al. 2006; Hölldobler et al. 2013), bees (Boch et al 1962; Shearer and Boch 1965) or wasps (Ono et al. 2003; Bruschini et al. 2008), which show the importance of the chemical alarm communication. In honeybee, these pheromones are released by the Koschevnikov gland which is situated in the abdomen, close to the sting shaft, and it provokes nestmates to attack and to sting the enemies (Breed et al. 2004). In termites, all known termite alarm pheromones are used for defensive purpose only and are produced by the frontal gland (Pasteels and Bordereau 1998; Šobotník et al. 2010a), an organ unique to Neoisoptera, a group comprising Serritermitidae, Rhinotermitidae and Termitidae (Noirot 1969; Quennedey 1984; Šobotník et al. 2010a). Although the chemical alarm communication occurs in many species (CostaLeonardo et al. 2009; Šobotník et al. 2010a), the alarm pheromones have only been identified in few species, namely in Prorhinotermes canalifrons (Rhinotermitidae), Velocitermes velox, Nasutitermes rippertii, $N$. corniger, $N$. princeps and Constrictotermes cyphergaster (all Termitidae: Nasutitermitinae) (see Šobotník et al. 2010a for a review, Cristaldo et al. 2015).

Although chemical and vibroacoustic signals are both widespread in social insects, few studies were devoted to understanding particular communication modalities. In termites, alarm can be propagated either through vibrations or/and pheromones, which makes them good candidates for detailed study, which has never been conducted up to now. We studied the alarm communication of Mastotermes darwiniensis, the most basal living termite, in order to test whether this species uses vibrational or chemical communication channels to spread the alarm. The particular phylogenetic position of M. darwiniensis, basal to all other termites, makes it a key candidate to understand the evolution of termite defensive strategies. Indeed, this species is the sole survivor of the 
formerly widespread family Mastotermitidae (Thorne et al. 2000; Wappler and Engel 2006) and diverged from all remaining termites about 150 million years ago (Bourguignon et al. 2015). M. darwiniensis is native to Northern Australia and shares several remarkable plesiomorphies with roaches, e.g. the anal lobe of hind wings, internal ovipositor, eggs arranged into ootheca or specialized fat body cells hosting symbiotic Blattabacterium (Nalepa and Lenz 2000; Grimaldi and Engel 2005). At the same time, $M$. darwiniensis reveals numerous traits often considered advanced like forked ontogenetic pattern (Watson et al. 1977) or efficient defensive strategy, including soldiers spitting in mandible-made wounds toxic secretion produced by the labial glands (Moore 1968), but do not possess the frontal gland of Neoisoptera. In other words, M. darwiniensis is often referred to as an example of mosaic evolution (Nalepa et al. 2001) and its advanced traits probably partially explain its invasive potential (Evans et al. 2013). We compared behavioural reactions of this species to several endangering stimuli, including human breath (Röhrig et al. 1999), crushed worker and soldier heads and artificially made vibratory and chemical signals, in order to decipher the structural components of the alarm communication. Here, we provide the results of an exhaustive study showing for the first time the functional significance of alarm communication in $M$. darwiniensis. Research on the most basal living termite is especially important as it allows understanding the evolution of defensive communication strategy in termites, which is a typical example of social communication improving the overall success of a group. Alarm communication is an evolutionary novelty of the Cryptocercus-Termitoidea clade and is one of the characters which differentiate termites from other roaches within Blattodea order.

\section{Methods}

\section{Termite collecting}

The studied colony of M. darwiniensis Froggatt 1897 was collected in North Australia and moved to the Federal Institute of Testing of Materials (BAM) in Berlin (Germany) in 1973. We have in two occasions transported fragments of this colony consisting of about 1000 workers and 300 soldiers to Prague, where they were kept at $26^{\circ} \mathrm{C}$, and used in experiments within 3 weeks after arrival. The first fragment was used for behavioural, chemical and vibratory experiments; the second fragment to test the effect of the main volatile compound detected using solid-phase microextraction (SPME) (for details see chemical analyses).

\section{Chemical analyses}

In order to decipher the chemical alarm signalling of $M$. darwiniensis and to confirm the composition of volatiles released by termites (see Moore 1968 and Sillam-Dussès et al. 2012), we carried out two chemical analyses. Firstly, we prepared extracts using five termites from each caste (workers and soldiers treated independently), which were cut at the level of prothorax, submerged into hexane and stored overnight at $4{ }^{\circ} \mathrm{C}$. This process was repeated twice in order to maximize the secretion extraction. One termite equivalent was injected in a $6890 \mathrm{~N}$ gas chromatograph (Agilent, Santa Clara, CA), and the most abundant compounds were identified based on spectral characteristics (cuticular hydrocarbons) and comparison to commercially available standards ( $p$-benzoquinone; purchased from Sigma-Aldrich Inc.). In the second analysis, the headspace extraction of volatiles was carried out using SPME fibre holder for manual sampling equipped with a fused silica fibre coated with $30 \mu \mathrm{m}$ polydimethylsiloxane (Supelco, Bellefonte, USA). The termites (three individuals for each caste, treated independently) were crushed in a 2-mL glass vial with a Pasteur pipette with broken tips and left in the vial. The vial was sealed, the holder needle was passed through the vial septum and the fibre was exposed for $10 \mathrm{~min}$ at room temperature. The analytes were desorbed at $220{ }^{\circ} \mathrm{C}$ in a split/splitless injector of a 5975B quadrupole mass spectrometer coupled to a gas chromatograph. The separation was achieved on a DB-5ms capillary column $(30 \mathrm{~m} \times$ $0.25 \mathrm{~mm}$, a film thickness of $0.25 \mu \mathrm{m}$, Agilent) at a constant flow mode $(1 \mathrm{~mL} / \mathrm{min})$ with helium as a carrier gas. The temperature program was $40{ }^{\circ} \mathrm{C}(1 \mathrm{~min})$, then $5^{\circ} \mathrm{C} / \mathrm{min}$ to $200{ }^{\circ} \mathrm{C}$, then $15{ }^{\circ} \mathrm{C} / \mathrm{min}$ to $320{ }^{\circ} \mathrm{C}(3 \mathrm{~min})$. The temperatures of the transfer line, ion source and quadrupole were 280, 230, and $150{ }^{\circ} \mathrm{C}$, respectively. The compounds were ionized by $70 \mathrm{eV}$ electrons. The dominant volatile compound (about half of the total quantity of detected compounds), identified as $p$-benzoquinone, was then used in behavioural experiments to test whether it acts as an alarm pheromone.

\section{Behavioural experiments}

The behavioural experiments were carried out on groups of 12 workers and 2 soldiers placed in Petri dishes $(\varnothing=85 \mathrm{~mm})$ with moistened filter paper disks (Whatman no 1) and a piece of birch wood as natural substrate. The group composition reflects not only the natural caste ratio (for review see Haverty 1977) but also ideal number of termites per Petri dish of a given size in order to maximize their interactions causing higher survival (see Miramontes and DeSouza 1996). The tested stimuli were introduced through a fine slit in the lid of the Petri dish. Prior to each experiment, the groups were conditioned at $26{ }^{\circ} \mathrm{C}$ under red dimmed light for at least $2 \mathrm{~h}$. All experiments were recorded using a Canon EOS 6D camera 
combined with a Canon EF $100 \mathrm{~mm}$ f/2.8L Macro IS USM lens set on a tripod above the Petri dish. Each record started $1 \mathrm{~min}$ before the introduction of the stimulus and ended $6 \mathrm{~min}$ after in order to evaluate the changes in behaviour due to the stimulation. This duration was chosen based on preliminary observations, as a compromise between too-short recording (record may end before the alarm spreads through the group) and too-long recording (results would be affected by alarm fade-out at the end), similar to previous study on the same topic (see Šobotník et al. 2008a).

Our stimuli included a blow of air (blowing inside with a fine glass straw for $3 \mathrm{~s}$ ), crushed worker head and crushed soldier head. Both castes were decapitated, heads crushed against a piece of filter paper $(3 \times 10 \mathrm{~mm}$; Whatman no. 1$)$ with a microspatula (cleaned between each tests) and the labial gland secretion removed by a light pressure against the decapitated body with the fluids released onto the same paper (blank filter paper piece as a control). All filter paper pieces were hung through the slit in the lid out of the reach of termites during the tests. Each experimental group was tested twice (with at least $2 \mathrm{~h}$ span between the tests) with different stimuli in random order. In total, we tested 12 groups, and the total number of repetitions per stimulus was always 6 (made with six different groups).

The responses to each stimulus were evaluated by the speed of termite walking, recounted into millimetres per second $(\mathrm{mm} / \mathrm{s}$ ) from Mouse-Tracer software outcomes (for details see Šobotník et al. 2008a). To normalize the mean speed of motion, we calculated the difference between the mean speed before and after the introduction of a stimulus. This method allowed normalizing the variance between different groups of termites. Two workers and the two soldiers were evaluated in each group. Traced workers were the two closest individuals to the slit in the lid at the beginning of experiment, irrespectively of their subsequent behaviour. We also recorded the number of mandible openings by soldiers after introduction of the stimulus, since this behaviour is in Kalotermitidae and Rhinotermitidae regarded as a sign of excitement of termite soldiers (Šobotník et al. 2008b; Hertel et al. 2011). Because vertical OMs were performed quickly without any change of the body position, only longitudinal OMs could be observed in behavioural experiments. The occurrence of all OMs was scored only during the vibroacoustic analyses (see vibratory communication for further details).

In order to test the role of the most dominant volatile compound (identified using the SPME; for details see above), we used $p$-benzoquinone (purchased from Sigma-Aldrich, Inc.) diluted in methanol in two concentrations ( 1 and $10 \mu \mathrm{g} / \mu \mathrm{L})$. As stimuli, we used $3 \mu \mathrm{L}$ of these two dilutions applied on a piece of filter paper $(3 \times 10 \mathrm{~mm}$; Whatman no 1$)$. Other stimuli consisted of one worker or one soldier equivalent acquired from extract of dissected labial glands in $3 \mu \mathrm{L}$ of methanol solution. Solvent control consisted in $3 \mu \mathrm{L}$ of pure methanol.
Each stimulus was presented randomly to new experimental groups of termites $(N=6)$ as described above.

\section{Vibroacoustic experiments}

Vibroacoustic experiments were carried out in an anechoic room designed to absorb all sound reflections inside and isolated from outside sounds and vibrations. All tests were performed on a table fixed to the ceiling to prevent any ground vibratory perturbation from experimenters, under red light conditions. Tests were performed in Petri dishes covered by moistened filter paper, on groups of termites consisting of 12 workers and 2 soldiers. Signals were recorded by highly sensitive accelerometers (Brüel\&Kjær type 4507 B 005) that were glued to the bottom of Petri dishes. The signals from the accelerometers were saved using a Soft $\mathrm{dB}$ Tenor recorder (24 bits, sampling frequency $48 \mathrm{kHz}$ ) connected to a computer and analysed using Matlab (R 2012a; see ESM 1).

The evaluated experiments were preceded by preliminary tests that served to determine the frequency band of vibroacoustic alarm behaviour in $M$. darwiniensis. To do so, we recorded alarm behaviour induced with a blow of air with the accelerometer and the camera placed above the Petri dish under normal light conditions. Some of the preliminary tests were done in Petri dishes of reduced heights, to test whether $M$. darwiniensis drummed to the bottom, ceiling or both. For this purpose, an additional accelerometer was attached to the lid of the Petri dish. Vibrations of the Petri dish were recorded and, based on the analysis of correspondence between the video records and the vibratory signals, we determined that the frequency band of 10 $200 \mathrm{~Hz}$ was excited by the vibratory movements of termites and not by other behaviours (i.e. walking or chewing). Consequently, only this frequency band was analysed during subsequent data processing.

Subsequently, we disturbed $M$. darwiniensis groups $(N=8)$ and analysed the vibratory communication within each tested group in order to test if a strong disturbance could trigger vibratory behaviour in $M$. darwiniensis. Energy of the vibratory signals $E_{\mathrm{R}}$ was counted using the following equation:

$$
E_{\mathrm{R}}=\frac{T_{\mathrm{B}} \int_{0}^{T_{\mathrm{A}}}\left|x_{\mathrm{f}}(t)\right|^{2} \mathrm{~d} t}{T_{\mathrm{A}} \int_{-T_{\mathrm{B}}}^{0}\left|x_{\mathrm{f}}(t)\right|^{2} \mathrm{~d} t}
$$

where $T_{\mathrm{A}}$ is evaluation period after disturbance (360 s), $T_{\mathrm{B}}$ is evaluation period before disturbance $(60 \mathrm{~s})$, and $x_{\mathrm{f}}(t)$ is filtered acceleration signal, where $x_{f}$ is a function of time $(t)$. This ratio represents a measure quantifying 
communication using the level of substrate-borne vibrations and is used throughout our paper.

We also tested the sensitivity of termite groups $(N=15)$ to computer-made vibratory sequences based on termite vibratory communication signals. We recorded the responses to assess the termites' reaction to a natural signal in comparison with a non-natural signal. We used Petri dishes with accelerometers (see above) fixed by a holder to the body of an electrodynamic shaker (Tiravib S50009) to induce vibrations. The shaker generated vibrations by hitting the Petri dish close to the centre (next to accelerometer) with a rubber head tip. Signal reproduction was optimized and the signal was of the same intensity as the termite-induced signals. This setting allowed simultaneous recording of both the computer-made signals and the termite responses to them. We introduced two different kinds of vibratory signals in random order:

(A) Computer-made imitation of natural signal ("natural" signal hereafter) developed according to innate signalling of M. darwiniensis. The "natural" sequence was the typical $M$. darwiniensis vibratory signal based on the average number of series (number of bursts, $S_{\text {avg, }}$, equal to 13 ), the average number of beats per bursts ( $B_{\text {avg }}$, equal to 3 ) and the average duration between beats ( $D_{\text {avg }}$, equal to $55 \mathrm{~ms}$ ) during $30 \mathrm{~s}$ of recording just after the preliminary stimulation by a blow of air.

(B) The control was a computer-made sequence of beats developed according to uniform distribution ("artificial" signal hereafter). This sequence contained the same total number of beats as the natural signal, but they were introduced with random time intervals between subsequent beats.

Statistical analyses for the behavioural experiments were performed using Kruskal-Wallis and two-by-two permutation post hoc tests for independent samples. The Bonferroni-Holm correction (Holm 1979) was applied for multiple comparisons among groups, and thus we used a corrected $P$ value named $P^{\prime}$ in such cases. For the vibroacoustic study, the computed differences in $E_{\mathrm{R}}$ were processed using permutation tests for paired samples $(10,000$ permutations). All statistical tests were performed with StatXact software (Cytel Studio, version 9.0.0, 2010).

\section{Results}

\section{Alarm behaviour}

We observed that $M$. darwiniensis used a complex alarm communication system, and the directly observable reactions to more intense stimuli consisted of workers running away from the source of disturbance and spreading the alarm signals to the nestmates (workers and soldiers) using series of contact vibrations (bumps). A few soldiers also reacted to disturbance by vibrating, but most of them faced the disturbance source with repeated openings of mandibles, during which the colourless labial gland defensive secretion (see Moore 1968) was released and coagulated into lumps of milky secretion, which gradually turned darker (see ESM_2).

Two kinds of vibratory behaviour could be recognised in both workers and soldiers. The most common alarm signal consisted in body shaking during which the abdomen repeatedly hits the substrate (but not the ceiling), very similarly to a vertical OM sensu Howse (1964, 1965b). The vertical OMs were performed either alone or followed by bumps into nestmates. Interestingly, vertical OMs were generally performed in isolation from other nestmates, while bumps were usually directed towards nestmates, with only occasional contact of abdomen on the ground, creating singular beats among vertical OM series.

\section{Behavioural reactions to disturbing stimuli}

Our analyses of the speed of motion revealed significant differences after stimulations in comparison with control for the workers (Kruskal-Wallis test $\mathrm{H}_{3}=12.75, P=0.03$ ) and for the soldiers (Kruskal-Wallis test $H_{3}=13.07, P=0.002$ ).

M. darwiniensis workers moved faster when exposed to a blow of air or to a crushed nestmate head (see Fig. 1a). Soldiers walked faster when exposed to the content of a crushed soldier head or after exposure to the content of a crushed worker head (see Fig. 2a). The number of mandible openings in soldiers also significantly differed between stimuli (Kruskal-Wallis test, $H_{3}=11.78, P=0.006$, see Fig. $1 \mathrm{~b}$ ) and was especially marked in response to $30 \mu \mathrm{g}$ of $p$-benzoquinone and crushed soldier head. This behaviour could not be studied in workers due to the short length of mandibles.

\section{Behavioural reaction to the main volatile compound of $M$. darwiniensis soldiers}

The GC/MS analyses of hexane extracts of $M$. darwiniensis workers and soldiers identified $p$-benzoquinone as the most abundant compound. SPME analyses confirmed that $p$-benzoquinone was the dominant volatile compound and was therefore a good alarm pheromone candidate. To test this hypothesis, we carried out a series of behavioural experiments and found a significant difference in speed of motion among stimuli for workers (Kruskal-Wallis test, $H_{4}=18.44, P<0.001$ ), which reacted to $30 \mu \mathrm{g} p$-benzoquinone dilution and soldier labial gland extract by increasing their speed (see Fig. 2a). While soldiers did not show any significant differences among stimuli regarding their speed of motion (see Fig. 2a), they displayed significantly higher number of mandibles openings when confronted to our stimuli (Kruskal-Wallis test, $H_{4}=$ $8.178, P=0.013$; see Fig. $2 b$ ). They performed more mandible openings when confronted to $30 \mu \mathrm{g} p$-benzoquinone dilution stimulus. They also displayed significantly more mandible 


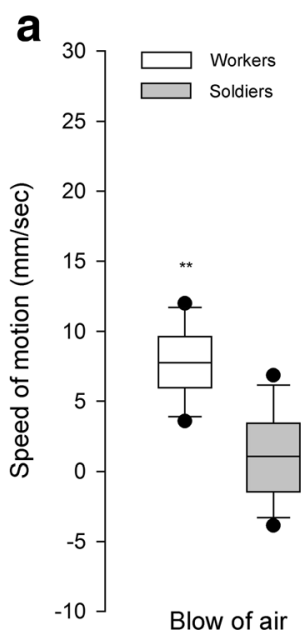

b
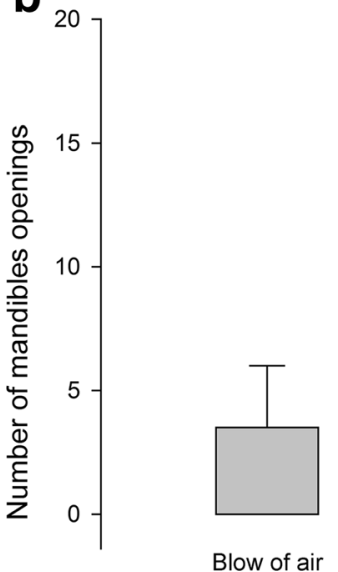
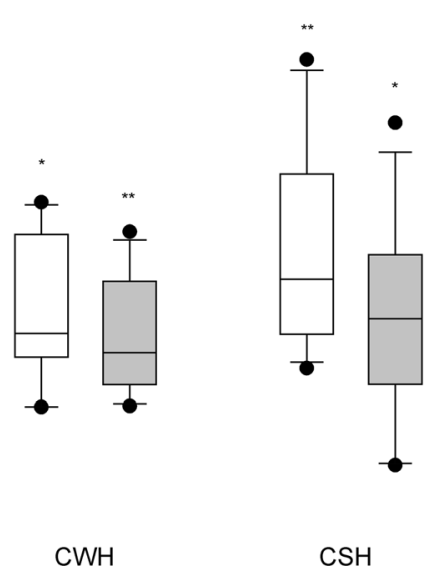

.

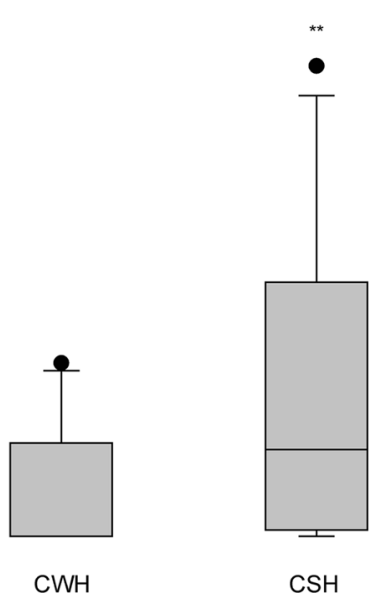

Fig. 1 a Speed of motion of M. darwiniensis workers (white bars) and soldiers (grey bars) after exposition to blow of air, crushed worker head $(\mathrm{CWH})$ and crushed soldier head $(\mathrm{CSH})$ in comparison with control; $N=$ 12 for each stimulus. Box plots show the median and 25-75th percentiles. Whiskers show all data excluding outliers outside the 10th and 90th percentiles (circles). Statistical significance, ${ }^{*} P^{\prime}<0.05$ and $* * P^{\prime}<0.01$. b Number of mandible openings of $M$. darwiniensis soldiers after exposition to blow of air, $\mathrm{CWH}$ and $\mathrm{CSH}$ in comparison with control (blank filter paper); $N=12$ for each stimulus. Box plots show the median and $25-75$ th percentiles. Whiskers show all data excluding outliers outside the 10th and 90th percentiles (circles). Statistical significance, $* * P^{\prime}<0.01$

openings when confronted to soldier labial gland equivalent $(P=0.047)$, but this result was not significant anymore after Bonferroni correction.

\section{Vibratory communication}

Observed vibrations in workers and soldiers could be separated in two different components (see Fig. 3). Vibratory sequences were performed very quickly, usually in less than $500 \mathrm{~ms}$. All recorded vertical OMs were uniform in appearance and consisted of series of two to seven beats (on average three beats) spaced by $55 \mathrm{~ms}$ span. On the other hand, bumps typically consisted in up to three forward jerks towards a

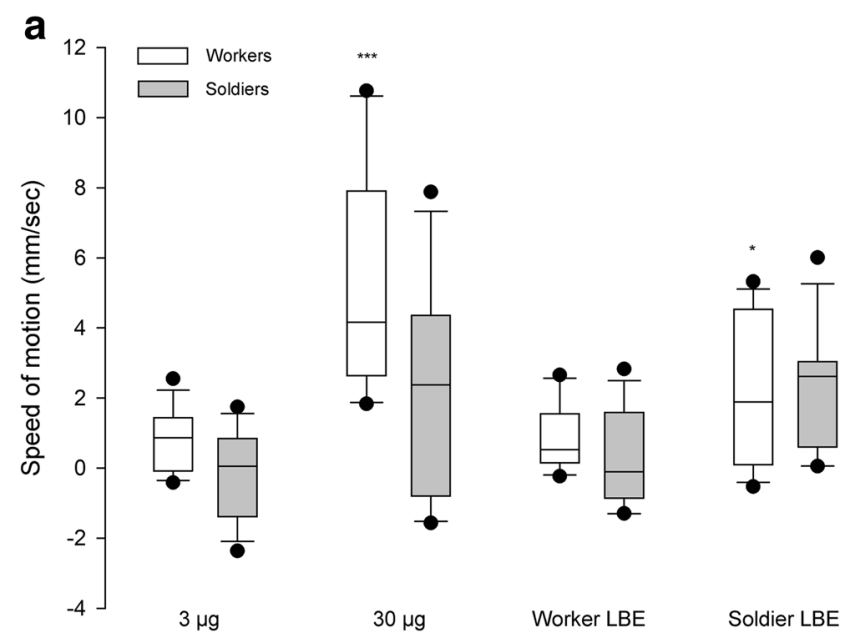

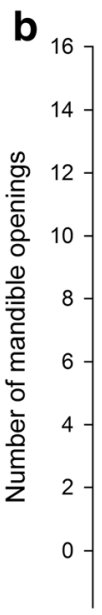

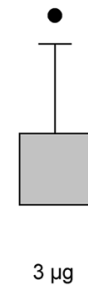

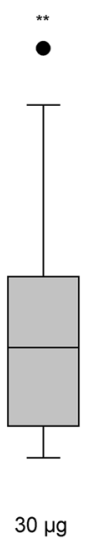

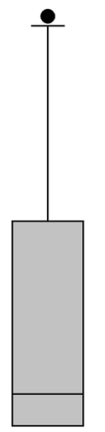

Worker LBE Soldier LBE

Fig. 2 a Speed of motion of M. darwiniensis workers (white bars) and soldiers (grey bars) after exposition to 3 and $30 \mu \mathrm{g} p$-benzoquinone concentrations and to worker and soldier labial gland extracts (worker LBE and soldier LBE, respectively), in comparison with control stimulation (pure methanol); $N=12$ for each stimulus. Box plots show the median and 25-75th percentiles. Whiskers show all data excluding outliers outside the 10th and 90th percentiles (circles). Statistical differences, $* P^{\prime}<0.05$ and $* * * P^{\prime}<0.001$. b Number of mandible openings of $M$. darwiniensis soldiers after exposition to 3 and $30 \mu \mathrm{g}$ $p$-benzoquinone concentrations and to worker and soldier labial gland extracts (worker LBE and soldier LBE, respectively), in comparison with control stimulation (pure methanol); $N=12$ for each stimulus. $B o x$ plots show the median and $25-75$ percentiles. Whiskers show all data excluding outliers outside the 10th and 90th percentiles (circles). Statistical difference, $* * P^{\prime}<0.01$

nestmate, sometimes accompanied by rapid antennal sweeps and occasional singular beats without specific association with vertical OMs; bumps were generally followed by vertical OMs and sometimes preceded them. Another difference between those two kinds of vibratory movements was that vertical OMs were uniform in energy value while bumps considerably differed in this aspect, as particular movements resulted in differing vigorousness of impacts to the surface (if any). 
Fig. 3 Example of vibratory behaviour of $M$. darwiniensis showing the typical structure of a vertical oscillatory movement $(\mathrm{OM})$ consisting of six beats and one longitudinal OM ended by a touch to the surface

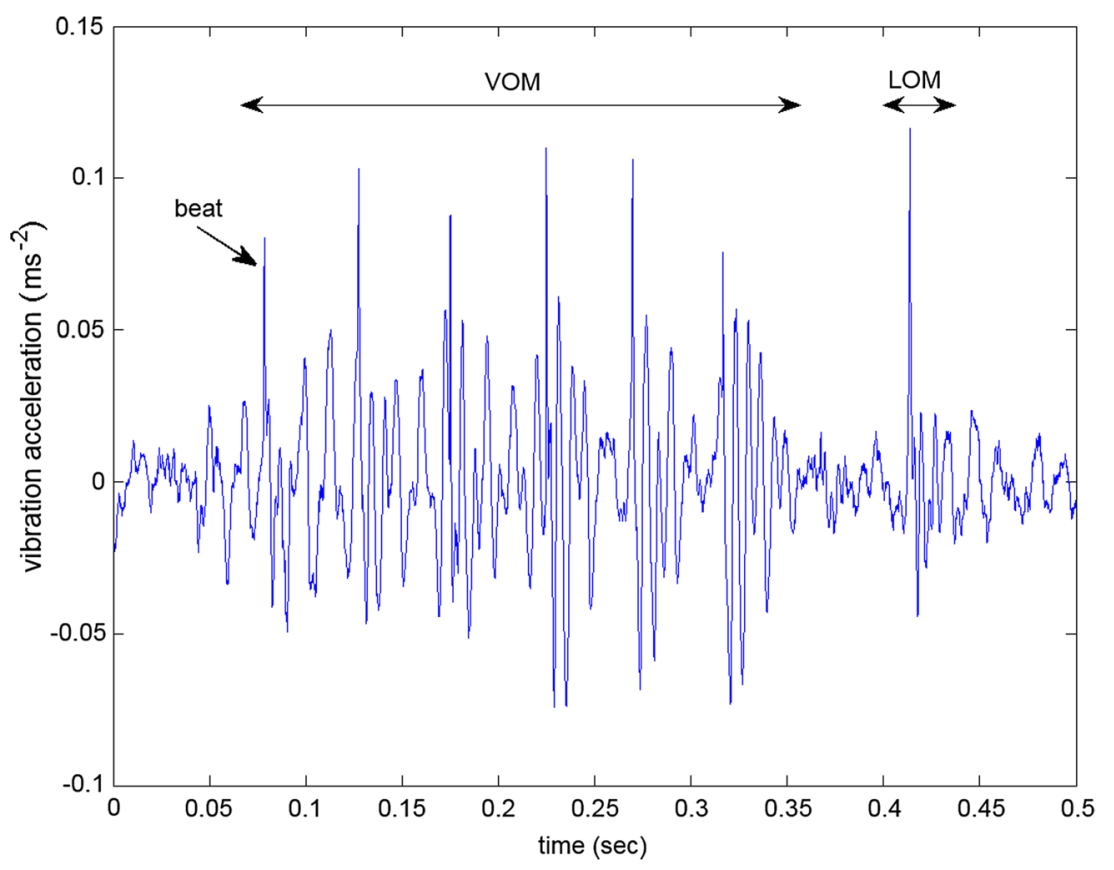

The tested groups performed more vibratory movements after stimulation by blow of air in comparison with control situation before the stimulation (permutation tests for paired samples, $t_{8}=-2.046, P=0.031$ ).

When confronted to computer-made signals (see Fig. 4), the tested groups produced significantly more vibrations when excited by the natural signal (permutation test for paired samples, $\left.t_{15}=-2.19, P=0.015\right)$, while the reactions were not

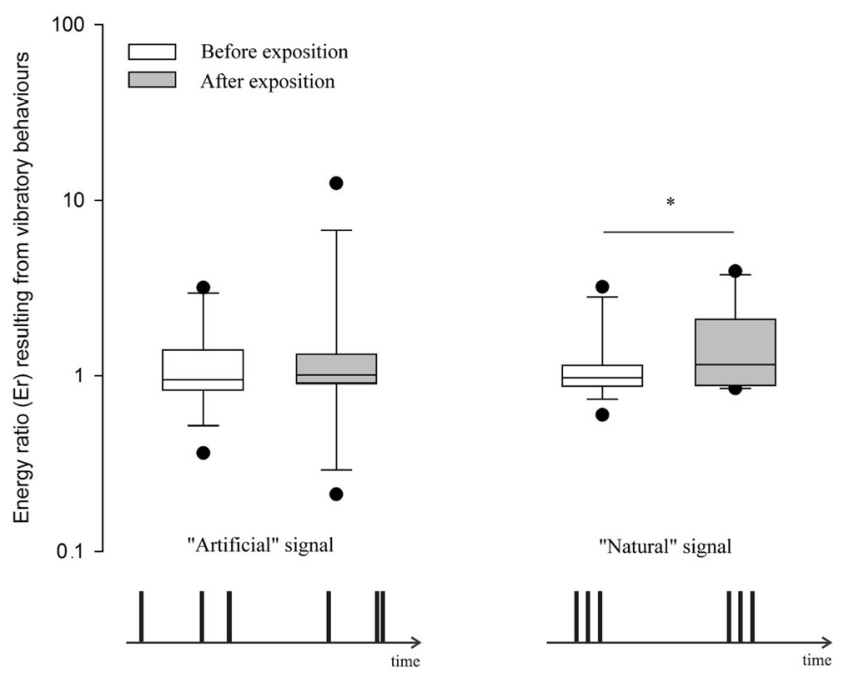

Fig. 4 Energy ratio (logarithmic scale) resulting from the vibrations recorded in $M$. darwiniensis termite groups $(N=15)$ before exposition and after exposition to computer-made signals ("artificial" and "natural"). The parameters of these signals were $S_{\text {avg }}=13$ in both, and $B_{\text {avg }}=3, D_{\text {avg }}=55 \mathrm{~ms}$ in natural signals only, while in artificial signals, the same total number of beats $\left(S_{\text {avg }} \times B_{\text {avg }}=39\right)$ was used, with random time interval between beats. Box plots show the median and 25-75th percentiles. Whiskers show all data excluding outliers outside the 10th and 90th percentiles (circles). Statistical difference, $* P<0.05$ significant after exposure to the artificial signal $\left(t_{15}=-0.857\right.$, $P=0.671$ ). Nonetheless, there was no significant difference between the reactions of groups after these two stimulations $\left(t_{15}=0.24, P=0.896\right)$.

\section{Discussion}

M. darwiniensis is the most primitive termite species (Bourguignon et al. 2015) and as such represent a key species to understand how alarm communication evolved in eusocial cockroaches. However, we already know that $M$. darwiniensis lives in populous groups monopolizing large foraging territories and revealing a multitude of other advanced characters, along with many plesiomorphies shared with cockroaches (see for example Emerson 1965; Moore 1968; Watson and Sewell 1985; Bandi, et al. 1995; Nalepa and Lenz 2000; Sillam-Dussès et al. 2007). Our results confirm the complexity of its social behaviour.

We indeed showed that $M$. darwiniensis used both vibratory and chemical cues as alarm signals. While vibroacoustic communication is considered to be an ancient channel and occurs in most insect taxa (Cocroft and Rodríguez 2005), chemical alarm communication is less common but occurs in most eusocial species (Blum 1969; Pasteels and Grégoire 1983; Vander Meer and Alonso 1998) as well as in some other insect groups, such as aphids (for review: Napper and Pickett 2008). In this study, we examined how alarm signals propagate and demonstrated the key role of vibroacoustic communication. Vibratory alarm communication is indeed known to occur in many termite species (Stuart 1988; Kirchner et al. 1994; Kettler and Leuthold 1995; Connétable et al. 1998, 
1999; Röhrig, et al. 1999; Hertel et al. 2011; Hager and Kirchner 2013), as well as in the cockroach Cryptocercus (Bell et al. 2007), the sister group of termites (Lo et al. 2000; Inward et al. 2007a). In fact, cockroaches dispose of a rich set of vibration-sensitive receptors located on tibiae, abdomen and cerci (Howse 1964; Shaw 1994) and have the ability to detect vibration. Additionally, basal termites and Cryptocercus live inside wood pieces suitable for the spread of vibrations, what probably favoured the evolution of vibratory communication in termites (Cleveland et al. 1934; see also Inward et al. 2007b).

Both workers and soldiers of $M$. darwiniensis respond to disturbance with vibratory signalling. This behaviour can be divided into vertical OMs (sensu Howse 1964) and bumpings, signals directed towards nestmates that almost always follow, and sometimes precede, vertical OMs. These two alarm modes are clearly not exclusive. Bumpings increase the efficiency of alarm propagation by alerting calm individuals, while vertical OMs are used to induce substrate-borne vibrations informing nestmates apart of the source of disturbance. These results are corroborated by the termite responses to computer-made signals of the same overall energy and technical characteristics (intensity and frequency content). Indeed, the amplification of termite vibratory signals was more common after exposition to natural than to artificial signals, showing that a specific temporal structure of the substrate-borne signal triggers a positive feedback in $M$. darwiniensis. This shows that even without direct contact vibrations, alarm can spread in the colony through the substrate. Positive feedback responses to vibrations produced by other nestmates have only been observed in several species of Termitidae (Connétable et al. 1999; Röhrig, et al. 1999; Hager and Kirchner 2013) but have never been demonstrated in any other termite family (Kirchner et al. 1994).

M. darwiniensis responds to released defensive compounds, and the pheromonal signal consists in $p$-benzoquinone. $p$-Benzoquinone is a component of soldier defensive secretion originated from the labial glands and spat from the mouth during the attack (Moore 1968; Quennedey 1984; Czolij and Slaytor 1988) but also in case of a strong disturbance, so a positive feedback mechanism also occurs in the chemical alarm signalling. The labial gland secretion is initially lucent but coagulates and quickly darkens at air exposure as $p$-benzoquinone tans the proteinaceous matrix (Moore 1968). The frontal gland was thought to be the only source of alarm pheromones in termites (Pasteels and Bordereau 1998; Šobotník et al. 2010a), but it is absent in $M$. darwiniensis. Our analyses confirmed the presence of $p$-benzoquinone in $M$. darwiniensis soldiers, but no volatiles were detected in workers although they are known to produce $p$-benzoquinone as well (Sillam-Dussès et al. 2012). The concentration of $p$-benzoquinone in worker secretion was probably lower, making it more difficult to detect with gas chromatography and
SPME. Even if the concentration of $p$-benzoquinone may not be sufficient for defensive purposes in workers, it may still play the role of pheromone. Indeed, hydroquinone, a related compound, is the food-marking pheromone and phagostimulant in several termite species including M. darwiniensis (Reinhard et al. 2002), and a role in communication could be expected from $p$-benzoquinone, which is a common product of hydroquinone spontaneous oxidization (see Monks et al. 1992). Other functions of workers' labial glands secretion comprise (i) food digestion (especially cellulolysis), (ii) feeding of dependent castes, and (iii) building activities (Noirot 1969; Grassé 1982; Tokuda et al. 2002; Fujita et al. 2008).

$p$-Benzoquinone is a very common defensive compound in arthropods due to its toxic properties (Blum 1981; Eisner et al. 2005) and is often used as a repellent (Eisner et al. 1978; Peschke and Eisner 1987; see also Weldon et al. 2003). Our observations show that excited soldiers may release by the mouth secretion containing $p$-benzoquinone that is perceived by other group members, and this in a dose-dependent fashion. Workers ran away when high dose of $p$-benzoquinone was presented and soldiers were alerted and spit up defensive secretion by repeated mandible openings. The pheromonal role of $p$-benzoquinone is unexpected, because of its strong irritating power, but this may have facilitated its use as an alarm medium which can be easily detected when released. Moreover, the vapour pressure of $p$-benzoquinone, which is a measure of its volatility, is very comparable to other common pheromones, with a $0.1 \mathrm{~mm} \mathrm{Hg}$ at $25^{\circ} \mathrm{C}$ (Lide 2005). This explains why this polar compound transported by water from the labial glands can perform the pheromonal function.

The reactions to crushed workers also triggered a significant behavioural change consisting in workers and soldiers increasing their speed, which suggests that workers can also spread chemical alarm. Interestingly, extracted labial glands alone did not exactly match our results, as exposition to it only increased the speed of motion in workers. This might be explained by inter-individual variability in behaviours, as our results for openings of mandibles in soldiers were not statistically significant only after the Bonferroni-Holm correction and more observations could reveal some increase of speed of motion in soldiers. Alternatively, the strong irritant nature of the compound may also explain its avoidance by workers which could be sensitive to it in the contrary to soldiers, as already hypothesized in other termites by Spanton and Prestwich (1981).

Soldiers tend to stay close to the disturbance source while displaying agonistic behaviours such as scanning the space with antennae, attacking aliens moving within their reach or releasing defensive secretion. Workers, on the other hand, tend to move away from the source of disturbance and signalize the alarm using either vertical OMs on the substrate or bumps directed towards calm nestmates. Although a complex 
defensive communication can hardly be observed at larger scale, we can draw some conclusions based on our results: (i) workers try to escape and hide away, and signalize the alarm during the retreat; (ii) soldiers move around the disturbed place, actively searching for enemies, releasing defensive secretion by the mouth and trying to bite any unknown object. Our field observations (Sillam-Dussès, Bourguignon and Šobotník, unpublished) indeed confirm this view, as soldiers of $M$. darwiniensis tend to stay on the substrate surface when foraging group is encountered while workers rather tend to disappear quickly.

In $M$. darwiniensis, alarm communication is based on two complementary sensorial channels whose use may be contextdependent. First, $p$-benzoquinone can be released when the colony is facing a danger in open air (like mammal predators digging the ground), as the compound triggers the escape of workers only and acts as a repellent on intruders (Moore 1968). Second, vibratory movements can be used inside the underground tunnels to inform close nestmates by longitudinal $O M s$ and distant by vertical OMs spreading the signal through the gallery. Similar behavioural modes are known not only in termites (Kettler and Leuthold 1995; Röhrig, et al. 1999; Šobotník et al. 2008b; Hager and Kirchner 2013) but also in wasps and ants where they occur in response to various threats including parasites (see Hunt and Richard 2013 for a review).

M. darwiniensis on one hand represents perhaps the oldest living eusocial lineage. However, it reveals rather advanced ontogenetic, ecological and communication traits, such as presence of true workers (Watson et al. 1977; Watson and Abbey 1985), living in populous colonies defending large foraging areas (Hill 1942; Goodisman and Crozier 2002) or using advanced alarm communication comparable in its complexity to crown group, the Termitidae, as we showed here. Its alarm strategy includes involvement of both soldiers and workers, while only soldiers specialize on spreading the alarm in Euisoptera clade. Our results introduce new insights into termite alarm communication at three different levels. First, individuals of $M$. darwiniensis respond to their own vibratory signals by spreading the information further, a phenomenon called positive feedback. Second, the alarm pheromone of M. darwiniensis is produced by the labial glands, unlike in other termites in which it is produced by the frontal gland that M. darwiniensis lacks. Third, the alarm pheromone of M. darwiniensis is a polar water-carried compound that carries alarm information probably through its irritating properties. Therefore, our results introduce an independent event of evolution of the chemical alarm communication in this basal family which diverged from all other termites some 150 million years ago (Bourguignon et al. 2015).

Acknowledgments We are grateful to R. Plarre and to the Federal Institute for Materials Research and Testing (BAM, Berlin) for kind providing of $M$. darwiniensis material. We also want to thank three anonymous reviewers for their constructive comments.

Funding Financial support was provided by the projects CIGA No. 20154320 and IGA No. B03/15 (Czech University of Life Sciences, Prague) and the BQR 2014/2015 from University Paris 13-SPC.

Conflict of interest The authors declare that they have no conflict of interest.

Ethical approval No specific permits were required for the study. M. darwiniensis is not listed as a vulnerable species by the IUCN. We used only material from the breeds of the BAM.

\section{References}

Bandi C, Sironi M, Damiani G, Magrassi L, Nalepa CA, Laudani U, Sacchi L (1995) The establishment of intracellular symbiosis in an ancestor of cockroaches and termites. Proc R Soc Lond B Biol Sci 259:293-299

Bell WJ, Roth LM, Nalepa CA (2007) Cockroaches: ecology, behavior, and natural history. The Johns Hopkins University Press, Baltimore

Bignell DE, Eggleton P (2000) Termites in ecosystems. In: Abe T, Bignell DE, Higashi M (eds) Termites: evolution, sociality, symbiosis, ecology. Kluwer Academic, Dordrecht, pp 363-387

Billen J (2011) Exocrine glands and their key function in the communication system of social insects. Formosan Entomol 31:75-84

Billen J, Morgan ED (1998) Pheromone communication in social insects: sources and secretions. In: Vander Meer RK, Breed MD, Espelie KE, Winston ML (eds) Pheromone communication in social insects: ants, wasps, bees, and termites. Westview, Boulder, pp 3-33

Blum MS (1969) Alarm pheromones. Annu Rev Entomol 14:57-80

Blum MS (1981) Chemical defenses of arthropods. Academic, New York

Boch R, Shearer DA, Stone BC (1962) Identification of iso-amyl acetate as an active component in the sting pheromone of the honey bee. Nature 195:1018-1020

Bourguignon T, Lo N, Cameron SL, Šobotník J, Hayashi Y, Shigenobu S, Watanabe D, Roisin Y, Miura T, Evans TA (2015) The evolutionary history of termites as inferred from 66 mitochondrial genomes. Mol Biol Evol 32:406-421

Bradshaw JWS, Baker R, Howse PE (1975) Multicomponent alarm pheromones in the weaver ant. Nature 258:230-231

Breed MD, Guzman Novoa E, Hunt GJ (2004) Defensive behavior of honey bees: organization, genetics, and comparisons with other bees. Annu Rev Entomol 49:271-298

Bruschini C, Cervo R, Protti I, Turillazzi S (2008) Caste differences in venom volatiles and their effect on alarm behaviour in the paper wasp Polistes dominulus (Christ). J Exp Biol 21:2442-2449

Chapman RF (1998) The insects-structure and function, 4th edn. Cambridge University Press, Cambridge

Cleveland LR, Hall SK, Sanders EP, Collier J (1934) The wood feeding roach Cryptocercus, its protozoa, and the symbiosis between protozoa and roach. Mem Am Acad Arts Sci 17:185-382

Cocroft RB, Rodríguez RL (2005) The behavioral ecology of insect vibrational communication. Bioscience 55:323-334

Connétable S, Robert A, Bordereau C (1998) Role of head-banging in alarm communication in two fungus-growing termites: Pseudacanthotermes spiniger and P. militaris. Act Colloq Insect Soc 11:117-124

Connétable S, Robert A, Bouffault F, Bordereau C (1999) Vibratory alarm signals in two sympatric higher termite species: Pseudacanthotermes spiniger and P. militaris (Termitidae, Macrotermitinae). J Insect Behav 12:329-342 
Costa-Leonardo AM, Casarin FE, Lima JT (2009) Chemical communication in Isoptera. Neotrop Entomol 38:1-6

Cristaldo P, Jandák V, Kutalová K, Rodrigues VB, Brothánek M, Jiříček O, DeSouza O, Jan Šobotník J (2015) The nature of alarm communication in Constrictotermes cyphergaster (Blattodea: Termitoidea: Termitidae). Biol Open. (in press)

Czolij RT, Slaytor M (1988) Morphology of the salivary glands of Mastotermes darwiniensis Froggatt (Isoptera: Mastotermitidae). Int J Insect Morphol Embryol 17:207-220

Deligne J, Quennedey A, Blum MS (1981) The enemies and defense mechanisms of termites. In: Hermann HR (ed) Social insects, vol 2. Academic, New York, pp 1-76

Eggleton P, Bignell DE, Sands WA, Mawdsley NA, Lawton JH, Wood TG, Bignell NC (1996) The diversity, abundance and biomass of termites under differing levels of disturbance in the Mbalmayo Forest Reserve, Southern Cameroon. Philos Trans R Soc Lond B 351:51-68

Eisner T, Alsop D, Hicks K, Meinwald J (1978) Defensive secretions of millipeds. In: Bertini S (ed) Handbook of experimental pharmacology, 48th edn. Springer, Berlin, Heidelberg, New York, pp 41-72

Eisner T, Eisner M, Siegler M (2005) Secret weapons: defenses of insects, spiders, scorpions, and other many-legged insects. Belknap, Cambridge

Emerson AE (1965) A review of the Mastotermitidae (Isoptera), including a new fossil genus from Brazil. Am Mus Novit 2236:1-46

Evans TA, Forschler BT, Grace JK (2013) Biology of invasive termites: a worldwide review. Annu Rev Entomol 58:455-474

Froggatt WW (1897) Australian Termitidae. Part II. Proc Linn Soc NSW 21:510-552

Fujita A, Miura T, Matsumoto T (2008) Differences in cellulose digestive systems among castes in two termite lineages. Physiol Entomol 33: $73-82$

Fujiwara-Tsujii N, Yamagata N, Takeda T, Mizunami M, Yamaoka R (2006) Behavioral responses to the alarm pheromone of the ant Camponotus obscuripes (Hymenoptera: Formicidae). Zool Sci 23: 353-358

Goodisman MAD, Crozier RH (2002) Population and colony genetic structure of the primitive termite Mastotermes darwiniensis. Evolution 56:70-83

Grassé PP (1982) Termitologia, tome 1. Masson, Paris

Grassé PP (1986) Termitologia, tome 3. Masson, Paris

Greenfield MD (2002) Signalers and receivers: mechanisms and evolution of arthropod communication. Oxford University Press, New York

Grimaldi D, Engel MS (2005) Evolution of the insects. Cambridge University Press, Cambridge

Hager FA, Kirchner WH (2013) Vibrational long-distance communication in the termites Macrotermes natalensis and Odontotermes sp. J Exp Biol 216:3249-3256

Haverty M (1977) The proportion of soldiers in termite colonies: a list and a bibliography (lsoptera). Sociobiology 2:199-216

Hertel H, Hanspach A, Plarre R (2011) Differences in alarm responses in drywood and subterranean termites (Isoptera: Kalotermitidae and Rhinotermitidae) to physical stimuli. J Insect Behav 24:106-115

Hill GF (1942) Termites (Isoptera) from the Australian region. Council for Scientific and Industrial Research, Melbourne

Hill PSM (2001) Vibration and animal communication: a review. Amer Zool 41:1135-1142

Hill PSM (2009) How do animals use substrate-borne vibrations as an information source? Naturwissenschaften 96:1355-1371

Hölldobler B, Plowes NJR, Johnson RA, Nishshanka U, Liu C, Attygalle AB (2013) Pygidial gland chemistry and potential alarm-recruitment function in column foraging, but not solitary, Nearctic Messor harvesting ants (Hymenoptera: Formicidae: Myrmicinae). J Insect Physiol 59:863-869
Holm S (1979) A simple sequentially rejective multiple test procedure. Scand J Stat 6:65-70

Howse PE (1962) The perception of vibration by the subgenual organ in Zootermopsis angusticollis Emerson and Periplaneta americana L. Cell Mol Life Sci 18:457-458

Howse PE (1964) The significance of the sound produced by the termite Zootermopsis angusticollis. Anim Behav 12:284-300

Howse PE (1965a) The structure of the subgenual organ and certain other mechanoreceptors of the termite Zootermopsis angusticollis (Hagen). Proc R Entomol Soc A 40:137-146

Howse PE (1965b) On the significance of certain oscillatory movements of termites. Insect Soc 12:335-346

Hughes WHO, Howse PE, Vilela EF, Goulson D (2001) The response of grass-cutting ants to natural and synthetic versions of their alarm pheromones. Physiol Entomol 26:165-172

Hunt JH, Richard F-J (2013) Intracolony vibroacoustic communication in social insects. Insect Soc 60:403-417

Inward DJG, Vogler AP, Eggleton P (2007a) A comprehensive phylogenetic analysis of termites (Isoptera) illuminates key aspects of their evolutionary biology. Mol Phyl Evol 44:953-967

Inward DJG, Beccaloni G, Eggleton P (2007b) Death of an order: a comprehensive molecular phylogenetic study confirms that termites are eusocial cockroaches. Biol Lett 3:331-335

Jouquet P, Dauber J, Lagerlof J, Lavelle P, Lepage M (2006) Soil invertebrates as ecosystem engineers: intended and accidental effects on soil and feedback loops. Appl Soil Ecol 32:153-164

Kettler R, Leuthold RH (1995) Inter- and intraspecific alarm response in the termite Macrotermes subhyalinus (Rambur). Insect Soc 42:145156

Kirchner WH (1997) Acoustical communication in social insects. In: Lehrer M (ed) Orientation and communication in arthropods. Birkhaüser, Basel, pp 273-300

Kirchner WH, Broecker I, Tautz J (1994) Vibrational alarm communication in the damp-wood termite Zootermopsis nevadensis. Physiol Entomol 19:187-190

Lide DR (2005) CRC handbook of chemistry and physics, internet version. CRC, Boca Raton

Lo N, Tokuda G, Watanabe H, Rose H, Slaytor M, Maekawa M, Bandi C, Noda H (2000) Evidence from multiple gene sequences indicates that termites evolved from wood-feeding cockroaches. Curr Biol 10: 801-804

Lo N, Engel MS, Cameron S, Nalepa CA, Tokuda G, Grimaldi D, Kitade O, Krishna K, Klass KD, Maekawa K, Miura T, Thompson GJ (2007) Save Isoptera: a comment on Inward et al. Biol Lett 3:562563

Miramontes O, DeSouza O (1996) The nonlinear dynamics of survival and social facilitation in termites. J Theor Biol 181:373-380

Monks TJ, Hanzlik RP, Cohen GM, Ross D, Graham DG (1992) Quinone chemistry and toxicity. Toxicol Appl Pharm 112:2-16

Moore BP (1968) Studies on the chemical composition and function of the cephalic gland secretion in Australian termites. J Insect Physiol 14:33-39

Nalepa CA, Lenz M (2000) The ootheca of Mastotermes darwiniensis Froggatt (Isoptera: Mastotermitidae): homology with cockroach oothecae. Proc R Soc Lond B Biol Sci 26:1809-1813

Nalepa CA, Miller LR, Lenz M (2001) Flight characteristics of Mastotermes darwiniensis (Isoptera, Mastotermitidae). Insect Soc 48:144-148

Napper E, Pickett JA (2008) Alarm pheromones of insects. In: Capinera JL (ed) Encyclopedia of entomology. Springer, Dordrecht, pp 85-95

Noirot C (1969) Glands and secretions. In: Krishna K, Weesner FM (eds) Biology of termites, vol I. Academic, New York, pp 89-123

Noirot C, Darlington JPEC (2000) Termite nests: architecture, regulation and defence. In: Abe T, Bignell DE, Higashi M (eds) Termites: evolution, sociality, symbioses, ecology. Kluwer Academic, Dordrecht, pp 121-139 
Ono M, Terabe H, Hori H, Sasaki M (2003) Components of giant alarm pheromone. Nature 424:637-638

Pasteels JM, Bordereau C (1998) Releaser pheromones in termites. In: Vander Meer RK, Breed MD, Espelie KE, Winston ML (eds) Pheromone communication in social insects. Westview, Boulder, pp 193-215

Pasteels JM, Grégoire J-C (1983) The chemical ecology of defense in arthropods. Annu Rev Entomol 28:263-289

Peschke K, Eisner T (1987) Defensive secretion of the tenebrionid beetle, Blaps mucronata: physical and chemical determinants of effectiveness. J Comp Physiol 161:377-388

Prestwich GD (1984) Defense mechanisms of termites. Annu Rev Entomol 29:201-232

Quennedey A (1984) Morphology and ultrastructure of termite defense glands. In: Hermann HR (ed) Defensive mechanisms in social insects. Praeger, New York, pp 151-200

Reinhard J, Clément JL (2002) Alarm reaction of European Reticulitermes termites to soldier head capsule volatiles (Isoptera, Rhinotermitidae). J Insect Behav 15:95-107

Reinhard J, Lacey MJ, Ibarra F, Schroeder FC, Kaib M, Lenz M (2002) Hydroquinone: a general phagostimulating pheromone in termites. $\mathrm{J}$ Chem Ecol 28:1-14

Richard F-J, Hunt JH (2013) Intracolony chemical communication in social insects. Insect Soc 60:275-291

Röhrig A, Kirchner WH, Leuthold RH (1999) Vibrational alarm communication in the African fungus-growing termite genus Macrotermes (Isoptera, Termitidae). Insect Soc 46:71-77

Shaw SR (1994) Re-evaluation of the absolute threshold and response mode of the most sensitive known "vibration" detector, the cockroach's subgenual organ: a cochlea like displacement threshold and a direct response to sound. J Neurobiol 25:1167-1185

Shearer DA, Boch R (1965) 2-Heptanone in the mandibular gland secretion of the honeybee. Nature 206:530

Sillam-Dussès D, Sémon E, Lacey MJ, Robert A, Lenz M, Bordereau C (2007) Trail-following pheromones in basal termites, with special reference to Mastotermes darwiniensis. J Chem Ecol 33:1960-1977

Sillam-Dussès D, Krasulová J, Vrkoslav V, Pytelková J, Cvačka J, Kutalová K, Bourguignon T, Miura T, Šobotník J (2012) Comparative study of the labial gland secretion in termites (Isoptera). PLoS One 7(10):e46431

Šobotník J, Hanus R, Kalinová B, Piskorski R, Cvačka J, Bourguignon T, Roisin Y (2008a) $(E, E)$ - $\alpha$-farnesene, an alarm pheromone of the termite Prorhinotermes canalifrons. J Chem Ecol 34:478-486

Šobotník J, Hanus R, Roisin Y (2008b) Agonistic behavior of the termite Prorhinotermes canalifrons (Isoptera: Rhinotermitidae). J Insect Behav 21:521-534

Šobotník J, Jirošová A, Hanus R (2010a) Chemical warfare in termites. J Insect Physiol 56:1012-1021

Šobotník J Bourguignon T, Hanus R, Weyda F, Roisin Y (2010b) Structure and function of defensive glands in soldiers of
Glossotermes oculatus (Isoptera: Serritermitidae). Biol J Linn Soc 99:839-848

Šobotník J, Bourguignon T, Hanus R, Demianová Z, Pytelková J, Mareš M, Foltynová P, Preisler J, Cvačka J, Krasulová J, Roisin Y (2012) Explosive backpacks in old termite workers. Science 33:436

Spanton SG, Prestwich GD (1981) Chemical self-defense by termite workers: prevention of autotoxification in two rhinotermitids. Science 214:1363-1365

Stuart AM (1988) Preliminary studies on the significance of headbanging movements in termites with special reference to Zootermopsis angusticollis (Hagen) (Isoptera: Hodotermitidae). Sociobiology 14:49-60

Thorne BL, Grimaldi D, Krishna K (2000) Early fossil history of the termites. In: Abe T, Bignell DE, Higashi M (eds) Termites: evolution, sociality, symbioses, ecology. Kluwer Academic, Dordrecht, pp 77-93

Tokuda G, Saitoh H, Watanabe H (2002) A digestive a-glucosidase from the salivary glands of the termite, Neotermes koshunensis (Shiraki): distribution, characterization and isolation of its precursor cDNA by 50- and 30-RACE amplifications with degenerate primers. Insect Biochem Molec Biol 32:1681-1689

Vander Meer RK, Alonso LE (1998) Pheromone directed behavior in ants. In: Breed M, Winston M, Espelie KE, Vander Meer RK (eds) Pheromone communication in social insects. Westview, Boulder, pp $159-192$

Wappler T, Engel MS (2006) A new record of Mastotermes from the Eocene of Germany (Isoptera: Mastotermitidae). J Paleo 80:380 385

Watson JAL, Abbey HM (1985) Development of neotenics in Mastotermes darwiniensis Froggatt: an alternative strategy. In: Watson JAL, Okot-Kotber BM, Noirot C (eds) Current themes in tropical science, vol. 3, caste differentiation in social insects. Pergamon, Oxford, pp 107-124

Watson JAL, Sewell JJ (1985) Caste development in Mastotermes and Kalotermes: which is primitive? In: Watson JAL, Okot-Kotber BM, Noirot C (eds) Current themes in tropical science, vol. 3, caste differentiation in social insects. Pergamon, Oxford, pp 27-40

Watson JAL, Metcalf EC, Sewell JJ (1977) A re-examination of the development of castes in Mastotermes darwiniensis Froggatt (Isoptera). Aust J Zool 25:25-42

Weldon PJ, Aldrich JR, Klun JA, Oliver JE, Debboun M (2003) Benzoquinones from millipedes deter mosquitoes and elicit selfanointing in capuchin monkeys (Cebus spp.). Naturwissenschaften 90:301-304

Wheeler JW, Evans SL, Blum MS, Torgerson RL (1975) Cycropentyl ketones: identification and function in Azteca ants. Science 187: 254-255

Wyatt TD (2003) Pheromones and animal behaviour. Communication by smell and taste. Cambridge University Press, Cambridge 